\title{
The Tangibility and Intangibility of e-Service Quality
}

\author{
Yun Ji Moon \\ Department of Management Information Systems, Catholic University of Pusan \\ yjmoon@cup.ac.kr
}

\begin{abstract}
This research aims to explore the effect of e-service quality on customer satisfaction and loyalty. Especially, the current paper focuses on customer perceptions and reactions to the tangible factors of e-service quality in the Business-to-Customer (B2C) area. This tangible eservice quality includes web design esthetics, ease of use, virtual tour, and visualization. In addition, intangible e-service quality involves information content, reliability, security, and customization. In order to investigate the interrelations among tangible and intangible $e$ service quality, customer satisfaction, and customer loyalty, the survey is conducted. Data from 468 tourists, who have purchased hotel packages during the last three months from hotel Web sites, is used for testing the hypothesized model. The result shows that the significant effect of tangible e-e-service quality on the intangible e-service quality and the significant effectiveness of e-service quality in improving customer satisfaction and loyalty.
\end{abstract}

Keywords: tangible e-service quality; intangible e-service quality; customer satisfaction; customer loyalty

\section{Introduction}

Web sites have proliferated since the emergence of the World Wide Web in the early 1990s. With the growth of the Internet, the world is on the threshold of revolutionary Web-driven change. Companies are still trying to come to terms with the remarkable challenge of e-business. Business-to-Consumer (B2C) electronic commerce, in which companies and customers engage in commerce via Internet-based technologies has generated a need to understand why internet users do or do not participate in ecommerce. Online companies' knowledge about user expectations can lead to a competitive strategy to seek profitable approaches to differentiation. Thus, in the current online competitive environment, exploring a new way to increase customer loyalty is closely connected to the issue of electronic service quality.

Traditionally, service quality (SERVQUAL) is conceptualized in service literature as the consumer's judgment about an entity's excellence or superiority. It is a type of attitude and involves tangibility, reliability, responsiveness, communication, credibility, security, competence, courtesy, understanding/knowing the customer, and access [1]. Based on these traditional service quality elements, e-SERVQUAL includes additional service functions derived from the online market: presale (the online retailer's efforts to provide product-related information to reduce customer's search cost), online sales (customer's purchasing activities), and after sales (delivery and problem solution) [2]. For instance, Lin [2] proposes e-commerce SERVQUAL as system quality of website design and interactivity, information quality of informativeness and security, and service quality of responsiveness, trust, and empathy.

Like interactivity or informativeness, service is intangible so that intangibility is the 
major distinction between services and tangible goods. Researchers conclude that intangibility is one of the most cited and critical topics of service literature because intangibility could increase customers' sense of risk and uncertainty toward services before their consumption [3]. During a Web-based service encounter, particularly, the interactions between service providers and customers might not take place. Therefore, intangibility may play a more critical role in the field of online services and bring managerial problems to service providers. With the recognition of the importance of intangibility, most e-SERVQUAL studies in the literature still focus on proposing and classifying intangible e-SERVQUAL elements to supplement service intangibility [4-6].

However, researchers $[3,7]$ have found that tangible cues in the service environment also decrease consumers' sense of intangibility after the encounter. For example, tangibility is defined by examining the extent to which hotel interiors are well decorated and whether the employees are dressed in uniforms where the clients are staying [1]. However, the previous tangible e-SERVQUAL only reflects the elements to satisfy existing consumers while neglecting to attract potential ones. Additionally, because intangibility leads to divergent expectation and evaluation models among consumers, tangible e-SERVQUAL could assist to unify, or at least to lower [3]. Therefore, this study attempts to explore how to solidify e-SERVQUAL model by proposing new tangible e-SERVQUAL dimensions.

\section{Theoretical Background}

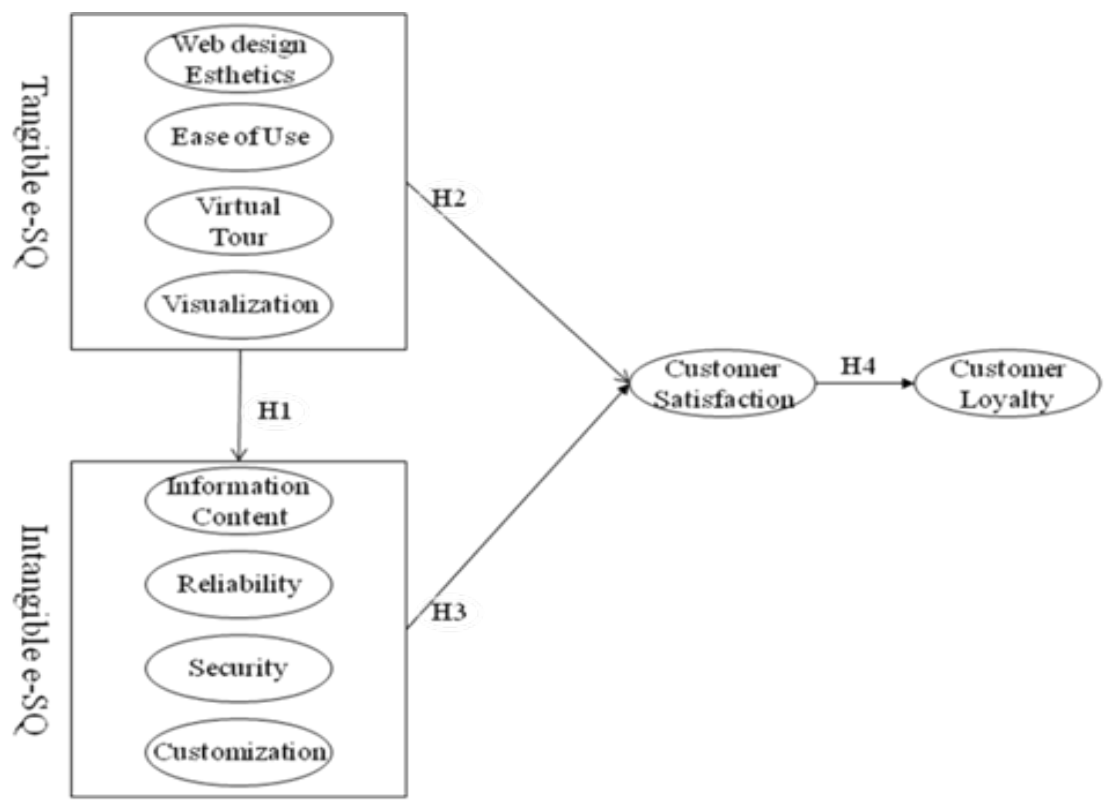

Figure 1. Research Model

Figure 1 summarizes our conceptual model. Although customer perception of service quality may differ across various settings, the perceptual process is basically an individual phenomenon, which may be affected by personal and environmental characteristics. Therefore, this study suggests that in/tangible e-SERVQUAL is an important determinant of customer satisfaction and loyalty. 


\subsection{E-Service Quality (E-SERVQUAL)}

Although a generic instrument to measure service quality has existed for some time [8], many have argued that click-and-mortar channels are so different from the traditional brick-and-mortar environment that a complete rethinking of e-SERVQUAL is required. E-SERVQUAL can be defined as the extent to which a Web site facilitates efficient and effective shopping, purchasing, and delivery [9, p. 217]. Along with the increasing recognition that service quality in the electronic environment is distinct and thus measurement should also be discrete from offline service quality, some studies have suggested e-SERVQUAL measurement items.

Examples include Barnes and Vidgen's WebQual [4], Parasuraman et al.'s E-SQUAL [9], and Lin and Wu [10]. Overall, previous research has failed to investigate the content of, and to clarify tangible e-SERVQUAL by focusing on intangible eSERVQUAL. For instance, Barnes and Vidgen [4] focus on a transaction-specific assessment of a site rather than a comprehensive view of service quality.

Although the E-S-QUAL framework by Parasuraman et al., [9] more extensively captures the nature of e-SERVQUAL from the perspective of online, the E-S-QUAL framework is still limited by its failure to take into account the tangible e-SERVQUAL factors, despite the existence of tangible factors in their original SERVQUAL model [8]. Thus, previous SERVQUAL studies do not properly identify the tangible eSERVQUAL.

However, research on the importance of physical cues such as aesthetic facility or layout for retailers of services in affecting customer response has existed for some time. The Internet presents a new challenge to reconsider the tangible cues in cyberspace, also called the e-scape [7] as more service encounters take place via Web sites instead of customer visits to retailers. Therefore, this study proposes a refined e-SERVQUAL model including tangible (or physical) as well as intangible e-SERVQUAL elements.

\subsection{Tangible and Intangible E-SERVQUAL Factors}

Generally, the tangible facets of service quality refer to the man-made physical environment [11]. Bitner [12, 13] proposes that the tangible environment has three components: design factors, social factors, and ambient factors. In offline environments, a design factor consists of architectural aesthetics and layout design. Huang, Li, and Zeng's e-SERVQUAL framework [14] suggests a Web design as one of the online tangible cues. According to previous studies, Web site design has two aspects. Some researchers regard a Web design as the Web site's aesthetics, indicating visual appeal. Others focus on ease of use. Web design aesthetics refers to the use of colors, graphics, and text that appeal to the customer's eye. Web design aesthetics can be used to make services more tangible, because customers' sense of the aesthetic design influences their perception of the products. On one hand, ease of use refers to the visitor's ability to navigate the Web site through a convenient Web interface. Good Web site design is characterized by good organization and easy searching. Aesthetic design also means offering uncluttered screens to consumers, simple search paths, fast presentations, clear organization, logical flow, and ease of navigation.

In addition, companies hope to maximize their online presence using the power of rich media where customers are researching products. Shih [15] asserts that a physical Web design enhances telepresence that is the extent to which individuals feel their existence in virtual space. Researchers have used the concept of telepresence to define virtual experience [16]. Mollen and Wilson [17] refine the concept of telepresence as 
"the psychological state of 'being there' in a computer-mediated environment, augmented by focused attention." For example, a virtual tour shows the visitor what something looks like. These virtual tours (for example, Disney World's virtual resort tour or Intercontinental Hotel's virtual package tour), can provide tourists with information about points of interest in their travel destination. Since tourism is a leisure travel activity, tourists need to know what activities are offered at their destination [18]. According to Cho [18], a virtual tour is an information search experience using visual images on the Web. According to previous studies, in this study, Web design refers to Web design aesthetics, ease of use, and virtual tours.

Next, social factors can be called as association factors or factualization [3]. Association factors are tangible elements of an object, place, event, product, and/or person. Providers use association factors to illustrate their services by a literal proclaimed statement, illustration, and representation such as figures, pictures, and images, properly setting and equipping at a point of service a demonstration of services, among others [3]. A visualization element of association attempts to get customers to picture the benefits of the service and to imagine experiencing the service [7, 19]. For example, Hilton Hotels Co. announced its sponsorship of the U.S. Olympic Team, which extended through the 2006 Olympic Winter Games in Toronto and the 2008 Olympic Summer Games in Beijing, China. The contract with the United States Olympic Committee (USOC) entitled the Hilton Family of Hotels to use the official hotel sponsor designation, and the U.S. Olympic Team and U.S. Paralympics Team logos in all advertising and marketing materials. Even if customers do not use these services, the sponsorship logo may lead to higher perceived expertise of the service provider and increase purchase intentions as much as actual advertisements do. Thus, when verbal information is low in imagery value, visual examples increased both immediate and delayed recall of product attributes. In this study, the tangible social factor is the vividness of visualization on a Web site.

Ambient factors consist of background characteristics that affect the non-visual senses and may have a subconscious effect on customers, such as aroma, lighting, or noise [12, 13]. Because customers cannot experience ambient elements such as aroma and temperature in the online context, this study excludes the adaptability of ambient factors. Finally, this study defines the tangible e-SERVQUAL as the online physical cues that facilitate services more tangibly through effective Web design including design aesthetics and ease of use, visualization, and virtual tours.

Furthermore, in order to examine the effects of in/tangible e-SERVQUAL dimensions, the present study adapts the intangible e-SERVQUAL scale proposed by Lin and $\mathrm{Wu}$ [10]- information content, reliability/response, security, and customization -because Lin and Wu's framework does not overlap with the tangible dimensions provided in this study. By modifying the intangible e-SERVQUAL variables proposed by Lin and $\mathrm{Wu}$ [10], this study integrates in/tangible dimensions into the e-SERVQUAL model and examines how both e-SERVQUAL variables will affect customers' perceptions and behaviors.

\section{Research Hypothesis}

\subsection{Tangible and Intangible E-SERVQUAL}

Perceived service quality is the consumer's perception of an entity's excellence or superiority. Most theories of human information processing are based on the assumption that information from the environment is received, encoded, and processed 
before a decision is made for the output. In terms of the information encountered when visiting a Web site, we propose that sensory stimuli of tangible cues are detected and identified before being processed. Subsequently, the physical cue, that is tangible eSERVQUAL, may elicit perceptual responses, that are intangible e-SERVQUAL, influencing people's evaluation and judgment of the quality of the product or service, namely perceived e-SERVQUAL. For example, if customers find a Web design attractive or a visualized brand symbol credible, these stimuli may positively affect the perception of intangible service quality such as accuracy of information and reliability with online retailers.

A body of work considers the influence of the physical factor (or environment) on customer service evaluations. Bitner [12] states that perceptions of physical factors influence beliefs about the environment itself, but also appear to affect beliefs about other, seemingly unrelated, service attributes. Rust and Oliver [20] also argue that the perception of service quality such as reliability is based on the customer's evaluation of physical service factors such as design. Sureshchandar et al., [11] propose that customers infer quality on the basis of their perceptions of physical factors so that tangible service quality influences intangible service quality. Thus, because services are intangible and often require the customer to be present during the process, the tangible/physical factors can have a significant influence on perceptions of the quality of the service encounter [12]. While most previous studies were conducted in the offline setting, in accordance with these considerations, we hypothesize the following in the online setting:

Hypothesis 1: The tangible e-SERVQUAL will have a positive effect on the intangible perceived e-SERVQUAL.

\subsection{E-SERVQUAL and Customer Satisfaction}

Customer satisfaction is a customer's perception of pleasurable fulfillment in a service. Parasuraman et al., [8] emphasize the transaction-specific nature of satisfaction in the sense that it is the emotional reaction following a disconfirmation experience, whereas service quality is an attitude and judgment of the customer's relatively enduring affective orientation for a product or service. If customers can be fully informed about the service concept, they can recognize what can be done, and why their needs or requests can or cannot be accommodated. Knowledge of the provided service reduces customers' perceived risk about a service provider, gives them confidence in that service provider, and fosters those customers' satisfaction.

With regard to the tangible factors of e-SEVQUAL, a majority of studies view eSERVQUAL as antecedents of customer satisfaction. Among them, web site design and ease of use are essential elements of consumer usage of computer technologies [21]. Web site design, or e-scape can be personalized to the user's needs and be decisive for customer satisfaction. Another tangible quality dimension directly related to the user interface is ease of use. Ease of use is particularly important for new user's satisfaction. One of the tangible factors that closely simulate actual experiences, on one hand, virtual experiences are likely to be the best available to increase user satisfaction [18]. Since providing virtual experiences help users to navigate through the environment, users spend less time for information acquisition and are more likely to be motivated to use web sites. Visualization which attempts to convey a vivid mental picture of a service provider's benefits or qualities helps consumers to overcome abstractness by evoking instances of a service's benefits. Therefore, when visualization cues are embedded, a 
service provider will offer higher quality to improve customer satisfaction. Considering previous literature on tangible e-SERVQUAL, this study suggests the following hypothesis:

Hypothesis 2: The perceived tangible e-SERVQUAL will have a positive effect on customer satisfaction.

Online retailers providing real-time services and customized information to customers may hold a competitive advantage in gaining a customer's repeat visits and satisfaction. In addition, many researchers have found that protecting Web security increases reliability of providers, and consequently improves satisfaction. Information content is another feature that can lead to final purchase. E-mail, help desks, and FAQs are the primary communication methods available on the Web to link customers and providers. E-mail and automated response are the dominant communication media in improving customer satisfaction. Better product information through better communication methods should help customers make wiser decisions and improve their e-satisfaction with and trust in a Web site.

Consequently, in order to improve customer satisfaction, online providers should provide the effective intangible e-SERVQUAL elements of beneficial information, online security, and customization realization. Based on the concepts of the intangible e-SERVQUAL, we suggest the following hypothesis on the relationship between perceived intangible e-SERVQUAL and customer satisfaction:

Hypothesis 3: The perceived intangible e-SERVQUAL will have a positive effect on customer satisfaction.

\subsection{Customer Satisfaction and Loyalty}

Although prospect theory views customer loyalty as an explanatory variable of satisfaction, a number of studies offer a rationale for why satisfied customers may be more loyal than dissatisfied customers [22]. Customer loyalty is a buyer's attachment or deep commitment to a product or service [21, p. 34], and this definition also can be applied to the B2C environment. Electronic customer loyalty is the customer's satisfaction with an electronic business, resulting in repeat purchasing behavior [22].

Overall, a significant positive relationship between satisfaction and loyalty has been confirmed. Although dissatisfaction with a single transaction does not cause customer switching, a dissatisfied customer is more likely to switch to a competitor than is a satisfied customer. While online customers cannot experience products/services directly, they can search for and compare numerous alternatives. Therefore, the relationship between satisfaction and loyalty is stronger online than offline [23]. Although it is difficult to gain loyal customers on the Internet, customer satisfaction with an online provider could motivate them to revisit and stay. Therefore, with respect to the effect of customer satisfaction on loyalty, we suggest the following hypothesis.

Hypothesis 4: Customer satisfaction will positively affect customer loyalty.

\section{Research Methodology}

\subsection{Measurement}

The e-SERVQUAL instrument in this study consists of two parts, one measuring tangible e-SERVQUAL and the other intangible e-SERVQUAL. This study adapts the 
measurement items of e-SERVQUAL from the previous studies. Researchers measure customer satisfaction and loyalty using items adapted from Ribbink et al., [21]. A seven-point Likert type scale is used for all of the measurement scale items, with anchors ranging from "strongly disagree" (1) to "strongly agree” (7). Respondents were asked to rate the appropriateness of the items in each scale. Minor modifications are based on comments collected through the pretest.

\subsection{Data Collection}

To test the hypotheses, we choose the lodging industry because it embodies some characteristics that are important for B2C services, such as in/tangible components. Potential participants, Zoomerang panel members who live in the USA and purchase online travel products, received an e-mail invitation to participate in this survey hosted by the Zoomerang Web site. The e-mail contains a hyperlink to the survey's Web site. Participants who agree to participate clicked the hyperlink to go directly to the online survey. The survey is completely voluntary and participants can withdraw from the online survey at any time without penalty. We ask the panelists whether or not they have purchased hotel package products such as hotel, airline, car rental, and other entertainment products for vacation purposes via a hotel's Web site during the past three months. Out of the 2,796 panelists, 1,084 surveys are returned. Of these 1,084 surveys, 389 are incomplete; therefore, 695 usable responses are retained. The 695 respondents are classified into two groups: 468 respondents who have booked hotel package products from a hotel Web site within the past three months and the remaining 227 respondents who have not. In this study, the 468 respondents are used for further data analysis.

\section{Results}

\subsection{Unidimensionality Assessment}

To assess the unidimensionality of each scale, internal consistency and confirmatory factor analyses are performed. First, a reliability test is used to purify the measurement scale for each construct. All coefficient alphas of the seven constructs report surpass .70 criteria for reliability acceptability. Items with weak contributions to coefficient alpha and low item-to-total correlations $(<.40)$ are dropped. To examine an acceptable fit of the proposed measurement model, each of the constructs is evaluated by examining the statistical significance of each estimated loading, and the overall model fit indices are evaluated. All loadings exceed .60, and each indicator $t$-value exceed $12.28(p<.001)$. The $\chi 2$ fit statistics show 1428.86 with 538 degrees of freedom $(\mathrm{p}<.01)$. RMSEA is .06 , less than the recommended .08 threshold and close to the recommended .05 cutoff. CFI and TLI values are respectively .95 and .94. Overall, all statistics support the measurement quality given the number of indicators.

Next, to assess discriminant validity, Fornell and Larcker [24] suggest using the square root of the average variance (AVE) shared between a construct and its measures. The evidence of discriminant validity exists when the diagonal elements (square root of AVE) exceed the off-diagonal coefficients in the corresponding rows and columns. One pair of scales with the highest correlation is ease of use and satisfaction $(\Phi=.39)$. Since the square root of average extracted estimate for ease of use and satisfaction is .55 and greater than .39 , discriminant validity is satisfactory. Therefore, according to this assessment, the measures have acceptable levels of validity. 


\subsection{Structural Equation Models and Hypotheses Testing}

The hypotheses of the research model are tested with a structural equation path model using AMOS version 18.0. The proposed model provides an adequate fit to the data, $\chi 2(364)=1478.20, p<.001$; CFI $=.92$; TLI $=.91$; RMSEA $=.08$. Overall, the proposed model explains $21 \%$ of the variance in intangible e-SERVQUAL [squared multiple correlation $(\mathrm{SMC})=.21 \mathrm{]}, 57 \%$ of the variance in customer satisfaction (SMC = $.57), 41 \%$ of the variance in customer loyalty (SMC $=.41)$. Within the model, the estimates of the structural coefficients provide the basic tests of the hypothesized relationships. The expected relationship between tangible and intangible e-SERVQUAL (Hypothesis 1$)$ is supported by the positive path coefficient $(\beta=.82)$, statistically significant at the $p<.001$ level. Tangible e-SERVQUAL affects customer satisfaction ( $\beta$ $=.32, p<.001$ ), thus supporting Hypothesis 2. Intangible e-SERVQUAL also has an effect on customer satisfaction $(\beta=.65, \mathrm{p}<.001)$ and Hypothesis 3 is supported. Next, the typical positive relationship between customer satisfaction and loyalty is supported $(\beta=.79, p<.001)$, confirming Hypothesis 4 .

\section{Discussions and Implications}

During the past two decades, conceptual work on service quality has shown dramatic progress. Although a number of studies highlight important aspects of service quality, ranging from Information Systems (IS) to marketing perspectives, the previous studies are unlikely to have fully captured the tangible e-SERVQUAL. To fill the gap, this study integrates tangibility and intangibility in understanding e-SERVQUAL. In the virtual environment, traditional intangible e-SERVQUAL variables such as sufficient information, online provider's reliability, security, and customization can be the critical factors in whether or not potential customers purchase products or services. However, rapidly developing Web technologies make it possible to communicate with customers in a multi-sensory virtual environment on the Internet in such a way that users of online media can feel present in the artificial environment created by the mediated information, namely, telepresence. Virtual tour and visualization are used to measure how tangible elements enhance online customers' telepresence.

In addition, this study clearly defines Web design as including both design aesthetics and ease of use. The results indicate that customers form tangible e-SERVQUAL perceptions based on their evaluations of four dimensions: design aesthetics, ease of use, virtual tour, and visualization. Actually, tourists who are interested in purchasing hotel package products that include a wide variety of intangible components, such as night shows and tour packages, face a high uncertainty in their purchase decisions before they actually see and experience their purchases. Under perceived high risk circumstances, a hotel's attractive Web site, along with its ease of use, visualized trustworthy logo, and virtual tour capability, can reduce customers' uncertainty by providing opportunities for a virtual experience of the hotel's services.

Second, our qualitative and empirical results show that tangible e-SERVQUAL is a significant determinant of intangible e-SERVQUAL composed of information content, security, reliability, and customization, as well as customer satisfaction. Designing and planning physical environments has been a significant topic in services marketing literature. While it is apparent that the physical environment factors positively affect customers' service quality perceptions in the offline context (for example, up-scale restaurants, fast food restaurants, and leisure facilities), extended studies are still required to examine, empirically, the relationship between tangible and intangible e- 
SERVQUAL in the B2C context. This study supports the notion that increasing the tangibility of intangible services should result in a more positive response and elicit more positive evaluations of the provided services. Making the service more tangible via pictures, virtual technology, or visualized service logo can increase customers' positive perceptions of provided information, customization, security, and reliability, and subsequently lead to a more positive response such as satisfaction. Accordingly, we also verify the intangible e-SERVQUAL elements such as customization, reliability, information, and security affect online customer satisfaction positively. Even if the Web undoubtedly offers strategic opportunities, the mechanism between tangible and intangible factors can be fully achieved only if service managers and Web site designers in hotels understand and realize the need to offer vivid Web sites that are attractively designed, convenient to use, and add a depth of sensory information to its virtual experiences. Thus, our model can greatly assist managers in understanding how their customers assess the quality of service experiences.

\section{Limitations and Suggestions for Future Research}

The limitations of our study offer opportunities for future research. First, our goal is to explore the relationship among in/tangible e-SERVQUAL, customer satisfaction, and loyalty. However, the effect of each tangible factor, such as design aesthetics and ease of use, on tangible e-SERVQUAL perception is not tested. The effects of four tangible factors can be different, and future research needs to identify the relative importance among the four factors in measuring customer perceptions of a Web site's service performance. In addition, further analysis of these interrelationships is needed in other contexts to establish more definitive proof of reliability and validity.

Second, the tangible e-SERVQUAL construct is operationalized in terms of design aesthetics, ease of use, virtual tour, and visualization. These tangible factors are tailored to hotels' Web site characteristics and did not reflect an ambient factor, while, in other industry contexts, the necessary tangible factors might be different. For example, ambient factors refer to background characteristics that tend to affect the non-visual senses - such as aroma, noise, or music-and may have a subconscious effect on customers $[12,13]$. In the online shopping mall, music can have a significant influence on online customers' responses. Research conducted by Morin, Dubé, and Chebat [25] supports the idea that music is an environmental, physically perceived parameter in an online service environment, highlighting the fact that music valence is transferred into customers' overall judgments on providers' quality. Therefore, future studies should consider the possibility that other tangible factors exist as important cyberscape elements.

\section{Acknowledgements}

This paper was supported by RESEARCH FUND offered from Catholic University of Pusan.

\section{References}

[1] A. Parasuraman, V. A. Zeithaml and L. L. Berry, “A conceptual model of service quality and its implications for future research”, Journal of Marketing, http://dx.doi.org/10.2307/1251430, vol. 49, (1985), pp. 41-50.

[2] H.-F. Lin, "The impact of website quality dimensions on customer satisfaction in the B2C e-commerce context”, Total Quality Management, http://dx.doi.org/10.1080/14783360701231302, vol. 18, (2007), pp. 363-378. 
[3] D. D. C. Tarn, "Raising services' tangibility in foreign markets via marketing: A model construction and a cross-national comparative empirical survey”, International Marketing Review, http://dx.doi.org/10.1108/02651330510602231, vol. 22, (2005), pp. 327-352.

[4] S. Barnes and R. Vidgen, "The E-Qual Approach to the assessment of e-commerce quality: A longitudinal study of Internet bookstores”, Edited W. Suh, Web engineering: Principles and techniques, Idea Group Publishing, http://dx.doi.org/10.4018/978-1-59140-432-3.ch007, (2004).

[5] M. A. Alanezi, A. Kamil and S. Basri, "A proposed instrument dimensions for measuring e-government service quality”, International Journal of u - and e - Service, Science and Technology, vol. 3, no. 4, (2010), pp. 1-18.

[6] H. Li and R. Suomi, “A proposed scale for measuring e-service quality”, International Journal of u-and eService, Science and Technology, vol. 2, no. 1, (2009), pp. 1-10.

[7] S. K. Koernig, "E-scapes: The electronic physical environment and service tangibility," Psychology \& Marketing, http://dx.doi.org/10.1002/mar.10065, vol. 20, (2003), pp. 151-167.

[8] A. Parasuraman, V. A. Zeithaml and L. L. Berry, "SERVQUAL: A multiple-item scale for measuring customer perceptions of service quality”, Journal of Retailing, http://dx.doi.org/10.1177/076737019000500102, vol. 64, (1988), pp. 12-40.

[9] A. Parasuraman, V. A. Zeithaml and A. Malhotra, "E-S-QUAL: A multiple-item scale for assessing electronic service quality”, Journal of Service Research, http://dx.doi.org/10.1177/1094670504271156, vol. 7, (2005), pp. 213-233.

[10] C. S. Lin and S. Wu, "Exploring the impact of online service quality on portal site usage", Presented at the 35th Hawaii International Conference on System Sciences, Honolulu, HI. http://dx.doi.org/10.1109/HICSS.2002.994223, (2002).

[11] G. S. Sureshchandar, C. Rajendran and R. N. Anantharaman, "Determinants of customer-perceived service quality: A confirmatory factor analysis approach”, Journal of Services Marketing, http://dx.doi.org/10.1108/08876040210419398, vol. 16, no. 1, (2002), pp. 9-34.

[12] M. J. Bitner, "Servicescape: The impact of physical surroundings on customers and employees”, Journal of Marketing, http://dx.doi.org/10.2307/1252042, vol. 56, (1992), pp. 57-71.

[13] M. J. Bitner, "Building service relationships: It’s all about promises”, Journal of the Academy of Marketing Science, http://dx.doi.org/10.1177/009207039502300403, vol. 23, no. 4, (1995), pp. 246-251.

[14] M. Huang, X. Li and X. Zeng, "Service quality in web 2.0 electronic commerce: An integrative perspective from typical service and technique-adoption”, International Conference on Wireless Communications, Networking and Mobile Computing, Shanghi, China,. http://dx.doi.org/10.1109/WICOM.2007.807, (2007).

[15] C.-F. Shih, "Conceptualizing consumer experiences in cyberspace”, European Journal of Marketing, http://dx.doi.org/10.1108/03090569810224056, vol. 32, (1998), pp. 655-663.

[16] A. Haque, R. Siddiqui, R. Javaid and I. M. Hussain, "Tele-presence Based Patient Monitoring Robot”, International Journal of Advanced Science and Technology, vol. 42, (2012), pp. 45-50.

[17] A. Mollen and H. Wilson, "Engagement, telepresence and interactivity in online consumer experience: Reconciling scholastic and managerial perspectives”, Journal of Business Research, http://dx.doi.org/10.1016/j.jbusres.2009.05.014, vol. 63, (2010), pp. 919-925.

[18] Y.-H. Cho, "The web-based virtual tour in tourism marketing”, Journal of Travel \& Tourism Marketing, http://dx.doi.org/10.1300/J073v12n04_01, vol. 12, no. 4, (2002), pp. 1-17.

[19] J. Gao, R. Ding, Y. Liu, B. Chen, B., X. Cui and J. I. Siepman, "Web-based visualization and analysis of atmospheric nucleation processes”, International Journal of u - and e - Service, Science and Technology, vol. 2, no. 2, (2009), pp. 25-38.

[20] R. T. Rust and R. L. Oliver, "Service quality: Insights and managerial implications from the frontier”, Edited R. T. Rust and R. L. Oliver, "Service quality: New directions in theory and practice”, Sage Publication, CA, http://dx.doi.org/10.4135/9781452229102.n1, (1994).

[21] D. Ribbink, A. Riel, V. Liljander and S. Steukens, "Comfort your online customer: Quality, trust, and loyalty on the Internet”, Managing Service Quality, http://dx.doi.org/10.1108/09604520410569784, vol. 14, (2004), pp. 446-456.

[22] S. S. Srinivasan, R. Anderson and K. Ponnavolu, "Customer loyalty in e-commerce: An exploration of its antecedents and consequences”, http://dx.doi.org/10.1016/S0022-4359(01)00065-3, vol. 78, no. 1, (2002), pp. 41-50.

[23] V. Shankar, A. Smith and A. Rangaswamy, "Customer satisfaction and loyalty in online and offline environments”, International Journal of Marketing Research, http://dx.doi.org/10.1016/S01678116(03)00016-8, vol. 20, (2003), pp. 153-175.

[24] C. Fornell and D. F. Larcker, "Evaluating structural equation models with unobservable variables and measurement error”, Journal of Marketing Research, http://dx.doi.org/10.2307/3151312, vol. 18, (1981), pp. 39-50. 
[25] S. Morin, L. Dubé and J-C. Chebat, "The role of pleasant music in servicescapes: A test of the dual model of environmental perception”, Journal of Retailing, http://dx.doi.org/10.1016/j.jretai.2006.10.006, vol. 83, (2007), pp. 115-130.

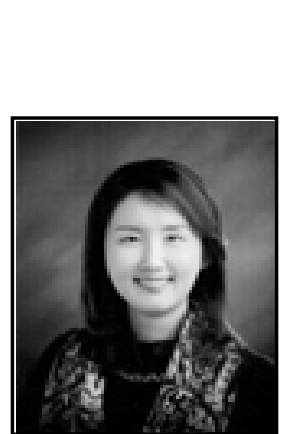

\section{Author}

Yun Ji Moon is an Assitant Professor in the Department of Management Information Systems, Catholic University of Pusan, South Korea. Her research interests include adoption of information technology, mobile business, organizational impact of information technology, knowledge management, and e-service quality model. Her papers have appeared in Canadian Journal of Administrative Sciences, Journal of Computer Information Systems, and International Journal of Hospitality Management and so on. She can be reached at yjmoon@cup.ac.kr. 
International Journal of Smart Home Vol.7, No.5 (2013) 